\title{
Ethical Dilemmas As Perceived By Healthcare Students With Teaching Implications
}

Janet R. Buelow, Armstrong Atlantic State University, USA

Pamela L. Mahan, Armstrong Atlantic State University, USA

April W. Garrity, Armstrong Atlantic State University, USA

\begin{abstract}
Ethical dilemmas are experienced by all individuals, but are especially prevalent among healthcare professionals. Universities and colleges preparing students to work and provide care in this arena are currently addressing this challenge through traditional ethics courses and lectures. However, student perspectives of the major ethical dilemmas in healthcare, as well as the differences among student disciplines, have not been identified. This study reports what students from six healthcare majors believe are the primary healthcare dilemmas today. Then, each healthcare discipline identified unique insights and implications of these dilemmas. These findings should lead to a consideration for more relevant ethics courses and curriculums within colleges and universities.
\end{abstract}

Keywords: ethical dilemmas, interdisciplinary learning, healthcare students

\section{INTRODUCTION}

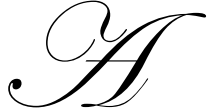

$s$ the US healthcare system struggles to provide high quality services to its diverse populations, healthcare professionals experience new and increasing ethical dilemmas. These dilemmas have a profound impact not only on clients receiving (or not receiving) care, but also on the healthcare workforce (Swetz, Crowley, Hook, \& Mueller, 2007). New graduates need the abilities and skills necessary to effectively manage their careers, as well as to care for others. As educators, we have the responsibility to prepare competent healthcare professionals by facilitating learning experiences that allow our students to understand and integrate the multiple perspectives of healthcare team members (Sporrong, Arnetz, Hansson, Westerhom, \& Hoglund, 2007).

Research on ethics education provides mixed outcomes on various educational methods for providing ethics content. Some programs provide individual courses, while others incorporate ethics education within the entire curriculum. Regardless of the process, ethics education incorporates similar goals, such as the ability to recognize moral conflicts, knowledge of ethical foundations and decision-making models (Gorgulu \& Kinc, 2007).

The purpose of this study was to identify the perspectives of students in multiple health professions concerning the ethical dilemmas encountered in the healthcare arena today. The specific questions we addressed are: What do students view as the major ethical dilemmas of healthcare today? How do students from different health profession disciplines differ in their perceptions of ethical dilemmas? It is anticipated that the results of this study will assist educators in developing a more effective ethics education paradigm incorporating the many and varied dimensions of healthcare today. 


\section{Ethical Concerns Identified by Specific Disciplines}

Our literature review started by identifying ethical dilemmas recognized by students in different healthcare disciplines. Although ethics courses abound within almost every disciplinary program, there are few studies that identify students' perspectives of ethical dilemmas in our overall healthcare system. However, several studies identified student opinions of ethical challenges within specific healthcare settings.

One study utilized journal entries to identify nursing students' perceptions of ethical dilemmas during maternal child nursing clinical rotations. Some of the ethical dilemmas identified within the journals were: practicing as a professional; lacking confidence as a student to take an ethical stand; advocating for patients and confronting the real world of healthcare (Callister, Luthy, Thompson, \& Memmott, 2009).

Geddes, Wessel and Williams (2004) also used physical therapy students' journals to identify ethical situations that arose during clinicals. Every student entry described an event, the events' value and their reaction to it. Three major themes were identified: respect for the uniqueness of individuals, professionalism ("responsibility and behavior as a member of the profession") and professional collegiality (interaction with and respect for health professionals). Minor themes included allocation of resources; advocacy for client and society; and informed consent.

Kenny, Lincoln, Blyth, and Balandin (2009) studied recent graduates in the profession of speech-language pathology (SLP) regarding their perceptions of ethical dilemmas. Four areas were identified: client management, professional relationships, service delivery and personal versus professional identity. Client management involved planning, treatments and discharge decisions. Professional relationships resulted from conflicts between duties or interactions with employers and clients or colleagues. Service delivery dilemmas were identified by fewer new graduates and involved the quantity and quality of services provided compared to health policy regulations. Personal and professional identity involved the new graduates' interpretation of their roles and responsibilities, as well as conflicting feelings regarding their professional roles and economic factors.

Nolan and Smith (1995) surveyed medical, nursing, and dental students at the commencement of their education in Great Britain. Students viewed a series of vignettes about a variety of ethical dilemmas in healthcare and then provided answers to a 29-item questionnaire consisting of both open and closed-ended questions. The most frequently listed ethical debates were abortion, prolonging life, assisting death (including euthanasia), resource allocation, health services management, and research using animal and human subjects. Issues raised by nursing and medical students were very similar, while medical and dental students identified worries about remuneration and career prospects. Also, nursing students focused more on the adequate provision of healthcare services for marginalized groups such as the elderly, mentally ill and those suffering from AIDS.

\section{Unique Ethics Education Programs}

For the second area of our literature review we explored unique ethics education programs within colleges and universities, specifically within the healthcare disciplines. Often the content of ethics courses was found in the literature, but we searched for creative programs which incorporated ethics education within one or more healthcare discipline. Three program descriptions follow.

The first program is the Program for Professional Values and Ethics in Medical Education (PPVEME) at Tulane University School of Medicine (Lazarus, Chauvin, Rodenhauser, \& Whitlock, 2000). The goals of the PPVEME were to provide a model learning environment emphasizing respect, empathy, professional character, effective communication, and an appreciation for the unique contributions made by each member of the healthcare team. Learning teams were composed of both faculty and students from each of the four years of medical school. The program began with a two-day retreat in which students wrote a personal mission statement, a mission statement for their group and a class mission statement. The teams met four times throughout the year, each taking turns teaching each other about a specific ethical concern. Outcomes were not evaluated, but effective strategies were identified. Effective strategies included short, interactive sessions; small group discussions, learning events led by students, and clearly defined goals for each well-planned activity. The least effective learning strategy was a 2 
hour session of movie-excerpt viewing with limited discussion within a large group of students.

Another unique program is from Hunter College School of Nursing and consisted of a 4-week program of integrating core professional values of nursing (CPNV) (Shaw \& Degazon, 2009). The emphasis was to explore the CPNVs, help apply them to the students' academic practice and integrate them into future clinical practice. The workshops included didactic presentations, group discussions, reflective writing and experiential learning. Student interviews reveal positive evaluations of the usefulness and relevance of their learning. The authors believed their preliminary findings suggest the need for more innovative methods to teach core values as a bridge for common understanding among diverse healthcare professionals.

Jensen and Richert (2005) investigated physical therapy (PT) student learning in a unique ethics course which used clinical cases, case analysis and theory application as tools for engaging students in analysis and reflection. Evaluation methods included: self-reflections following two videotaped standardized patient interactions; peer and self-assessments; pre and post test scores; as well as instructor reflections. All students demonstrated significant increases between pre- and post-tests on a self-efficacy ethics survey. However, student performance on the standardized patient interactions revealed that those students who were extremely confident in their interactions performed less critical self-reflection on their performance. The authors suggested some of the most important components of ethics education as 1) facilitating development of students' reflective capacity and 2) learning experiences that have clinical authenticity.

\section{METHODOLOGY SAMPLE AND PROCEDURES}

Using the Nolan and Smith study as a guide, we developed a similar survey instrument which addressed our research question; what do students view as the major ethical dilemmas of healthcare today? Surveys were conducted in two state universities, one in the Midwest and the second in the Southeast. We recruited a convenience sample of 440 students from 14 different health professions courses and have included in our sample all students with a minimum of thirty students in their health major for a final sample size of 356 . The health professions are medicine, nursing, healthcare administration, and physical, occupational and speech and language pathology therapies (Since some therapy majors were very small, all therapy students were grouped together to create comparable groups). The participating universities provided IRB approval. Completion of the survey was conducted at the end or beginning of a class period. The survey was explained as voluntary and consent to participate in the study was implied by completing the survey. Students had the option of writing "refused" on the instrument to avoid social pressure to participate. The overall response rate from students who completed at least half of the survey was $96 \%$.

Table 1 provides a description of our final sample of students. Students of all majors were approximately the same age, from 25 to 26 years. The nursing majors were primarily undergraduates, while therapy and healthcare administration students were split between undergraduate and graduate levels. The medical students were all first year graduate students. Student genders were divided by traditional healthcare roles, with the majority of nursing and therapy students being female.

Table 1: Description of the Health Professions Students

\begin{tabular}{lcccc}
\hline & Nursing & Therapy $*$ & $\begin{array}{c}\text { Healthcare } \\
\text { Administration }\end{array}$ & First Year Medical \\
\hline Total & 187 & 76 & 60 & 33 \\
Undergraduate students & $98 \%$ & $34 \%$ & $48 \%$ & $100 \%$ \\
Graduate students & $2 \%$ & $66 \%$ & $52 \%$ & 25.2 \\
Age mean years & 26.3 & 25.4 & 25.2 & $42 \%$ \\
Males & $11 \%$ & $11 \%$ & $30 \%$ & $58 \%$ \\
Females & $89 \%$ & $89 \%$ & $70 \%$ & \\
\hline
\end{tabular}

* Student majors include occupational therapy (9), physical therapy (16), and speech-language pathology (51). 
Along with some descriptive questions, this study analyzed the open-ended question, "What do you think is the major ethical dilemma in our healthcare system today? Professors from healthcare administration, nursing and speech and language pathology independently coded student responses and then met as a group to compare interpretations. Inter-coder reliability started at $60 \%$ and grew as subcategories within codes developed. These codes then were entered into the database and compared to the healthcare discipline of our student sample.

\section{FINDINGS}

The top three ethical dilemmas identified by clinical students (nursing, therapy and medical students) were: 1) the uninsured and underinsured;2) moral and religious issues and 3) public policies not controlling rising costs. While healthcare administration students identified these primary ethical dilemmas, they also identified a significant fourth dilemma as, fiscal concerns of healthcare organizations and providers. As Table 2 reveals, these general codes provide a starting point for student perspectives, but meticulous re-readings of each student's statements revealed unique sub-categories or insights into these areas which the students identified. These insights are briefly reviewed.

\section{The Uninsured and Underinsured}

The uninsured and underinsured was the most prevalent ethical dilemma identified by all student disciplines. About $40 \%$ of medical students and over thirty percent of all other healthcare majors identified this area as a major ethical dilemma. The general wording was often, the number of uninsured, lack of availability of affordable care and "not everyone having access to care." Fuller statements from the students revealed three aspects of this dilemma: 1) specific population pockets who are impacted more than the general population; 2) the impact of missing treatments and the resulting poor health status and 3) organizational and societal implications of treating the uninsured.

Students often identified the middle class and poor as the population pocket impacted the most. One nursing student stated, "Healthcare is harder to keep for the middle class or upper side of low income families" and another nursing student stated, "health insurance is hard to obtain for most working class and they are not being taken care of." Several nursing students identified the poor and those in poverty as being uninsured. A nursing student noted "the poor not having healthcare" and "lack of healthcare for those in poverty." A SLP student stated "people in lower socioeconomic areas not being able to get healthcare." A PT student wrote, "Providing healthcare to the uninsured who are typically minorities or those of low socio economical classes." Another PT student wrote "many low income individuals and families are not able to pay for health insurance or any sort of coverage."

Lack of insurance coverage clearly impacts the number of treatments and prescriptions a client receives and this was not missed by many of the clinical students. Identifying professional treatment implications, one nursing student wrote "...the availability of prescription medications for serious illnesses such as cancer, insulin shots and high blood sugar." Students often identified the client implications when speaking of their treatments. For example several students wrote that their professional actions or treatments were limited by lack of insurance and this had a subsequent negative impact on the health status of the patient or client. A nursing student stated "insurance coverage negatively impacting [a patient's] plan of care." A SLP student wrote "inaccessibility to treatment because of insurance company policies and restrictions." Another SLP student wrote "health insurance running out when patients still need treatment or therapy." A nursing student wrote, "Not administering optimal care to a patient who has no healthcare insurance." A PT student wrote, "making decisions based on the wealth of the patients." Another PT student wrote "inability to provide the most appropriate treatment due to insurance." Sometimes just providing care to the uninsured was identified. A medical student stated "treating or not treating patients without insurance." A nursing student wrote "people being turned away due to not having ability to pay" and "whether or not to treat those without a way to pay." A few students indicated that the uninsured are not treated as respectfully as the insured. One nursing student wrote, "the uninsured and the way they are treated in healthcare settings" A PT student wrote "...health insurance; whether patients have it or not and treating them differently."

The third subcategory of the uninsured is organizational and societal implications. The fewest number of students identified this, but each student provided powerful statements. A nursing student wrote, "Providing care to patients without health insurance and letting hospitals loose so much money." Another nursing student wrote, "Some 
healthcare facilities turn people away due to no health insurance. People need to pay, but no one should not be helped due to insurance." A healthcare administration student took the most global picture when he wrote; "Healthcare needs to be available to more people, because sick people cannot put back into the economy."

Table 2: Ethical Dilemmas Identified by Health Profession Students

\begin{tabular}{|c|c|c|c|c|c|}
\hline $\begin{array}{c}\text { Common } \\
\text { Ethical Dilemmas }\end{array}$ & Subcategories & Nursing & Therapy * & $\begin{array}{c}\text { Healthcare } \\
\text { Administration }\end{array}$ & Medical \\
\hline \multirow{4}{*}{$\begin{array}{l}\text { Uninsured \& } \\
\text { Underinsured }\end{array}$} & & $33 \%$ & $30 \%$ & $31 \%$ & $40 \%$ \\
\hline & Specific population pockets & Identified & Identified & & \\
\hline & $\begin{array}{l}\text { Omitted treatments \& health } \\
\text { implications }\end{array}$ & Identified & Identified & & Identified \\
\hline & $\begin{array}{l}\text { Organizational \& societal } \\
\text { implications }\end{array}$ & Identified & & Identified & \\
\hline \multirow{4}{*}{$\begin{array}{l}\text { Moral and } \\
\text { Religious Issues }\end{array}$} & & $28 \%$ & $12 \%$ & $18 \%$ & $31 \%$ \\
\hline & End of life issues & Identified & Identified & & Identified \\
\hline & Abortion & Identified & & & Identified \\
\hline & Stem cell research & Identified & Identified & Identified & Identified \\
\hline \multirow{3}{*}{$\begin{array}{l}\text { Public Policies not } \\
\text { controlling rising } \\
\text { costs }\end{array}$} & & $13 \%$ & $17 \%$ & $18 \%$ & $26 \%$ \\
\hline & $\begin{array}{l}\text { Medicare \& Insurance low } \\
\text { reimbursement rates }\end{array}$ & Identified & Identified & & Identified \\
\hline & Universal care concerns & Identified & Identified & Identified & Identified \\
\hline $\begin{array}{l}\text { Fiscal resilience of } \\
\text { organizations \& } \\
\text { providers }\end{array}$ & & $5 \%$ & $7 \%$ & $20 \%$ & 0 \\
\hline
\end{tabular}

That do you consider the major ethical dilemmas in healthcare today?

Identified $=$ Students in these disciplines identified the particular aspects of this ethical dilemma.

\section{Moral and Religious Issues}

Specific moral and religious issues were identified by about $30 \%$ of medical and nursing students and by $18 \%$ of healthcare administration students and $12 \%$ of therapy students. The top three issues, in chronological order, are end of life care, abortions and stem cell research. The end of life issues were worded quite diversely. Medical students wrote short phrases such as terminating ill patients, assisted suicide, pulling the plug, and "physician assisted suicide." Nursing students wrote phrases such as: right to die; letting patients pick what routes they want to go; deciding when care is still necessary or when patients should be put on a do not resuscitate (DNR) order; choosing your own time to die; when to end care for unresponsiveness; ventilated patients with minimal or very little brain activity; and when to let some just die versus life support. One SLP student stated the dilemmas today center around using different methods (some controversial) to save lives or increase the quality of life. Another SLP student wrote "scientific and technological innovations that extend or pressure life where it previously was not possible." One PT student took a different angle and wrote "excessive monetary gain in lifesaving." This was the only fiscal notation.

For the moral issue of abortion, both medical and nursing students identified abortion more than the other students. It was often unclear if students were for or against abortion as most wrote comments such as "abortion bill", "abortion rights", "abortion issues" and "the current ban on abortion." Stem cell research was the last moral issue mentioned by about half as many students as the first two issues. Students in all majors identified this issue with little variation in the terminology. 


\section{Public Policies Not Controlling Rising Costs}

Many students identified the failure of public policies to control rising costs as a significant challenge. Overall almost $20 \%$ of students identified this issue - with medical students $(26 \%)$ identifying this problem more than any other healthcare discipline. Most of the time students wrote just short phrases such as rising costs, overall healthcare getting to expensive, and how to pay for it.

One subcategory identified by many of the therapy students and a few of the nursing and medical students was low reimbursement rates by Medicare and other insurances. One SLP student wrote "the amount of care they should receive based on payment" and another SLP student wrote "limitations in the care that can be provided, imposed by third party payers." A PT student wrote "Payment/ billing decisions on best practices versus what makes money." Both nursing and therapy students noted denial of care issues. One nursing student wrote "a fundamental problem with health insurance companies is denying care and services to people" and a PT student wrote "reimbursement determining care of patients." An OT student wrote, "providing the care people need under a very constrained budget." Nurses also identified this as one nurse wrote "Medicare benefits are insufficient to cover meds and services," A medical student wrote, "the discrepancy between best care provided and minimal care provided by Medicare and health insurance." Another medical student wrote, "giving patients the best care while maintaining financial reason and patient compliance."

Within all student majors a few students had concerns about "universal care' or "socialized healthcare." However, for most students we couldn't identify their preferences as they just noted one of the above phrases. One nursing student clearly wanted something more as she wrote "I believe the government needs to become more involved with the cost of medicine today." Another nursing student wrote "There is not really a uniform set for rules throughout. We are getting behind many other countries."

\section{Fiscal Resilience of Organizations \& Providers}

Fiscal concerns of individual healthcare organizations and providers were identified by $20 \%$ of the healthcare administration students and a few of the other healthcare professions students. Healthcare administration students wrote comments such as "when profits take priority over peoples well being" and "profits before care" and "the drive for money may override the moral issue of taking care of the patient." A nursing student stated, "healthcare has become too much of a business, it is all about the money and should not be." Another nursing student stated, "putting personal gain, i.e. money, reputation, etc above administering optimal level of care for everyone."

Several comments were provided regarding providers. Two different healthcare administration students wrote, "The manipulation of reimbursement systems for the gain of the provider" and "Physicians recommending unnecessary procedures to boost their income." Several PT students identified this issue too. One PT student wrote "overbilling for services, findings ways to profit when reimbursement is becoming increasingly difficult." Another PT student wrote "Conflict of doing what will make money versus what is best for patient care (giving best care)." A different PT student wrote "Billing for treatments that shouldn't be billed for. Also not following evidence based practice."

\section{DISCUSSION}

Many of our findings support what was found in previous studies reviewed earlier. These studies identified ethical issues of inadequate care for marginalized groups; worries about remuneration for providers; allocation of resources and advocacy for clients; and the quantity and quality of services provided within policy regulations. Our students also identified these issues: population pockets impacted by lack of insurance; the fiscal resilience of organizations and providers; public policies not controlling rising costs; low reimbursement rates; and omitted treatments \& health implications for individuals. Even specific moral and religious issues such as abortion and end of life issues our students identified as major ethical dilemmas were identified by UK healthcare students as ethical dilemmas (Nolan \& Smith, 1995). 
Our study contributes new information with the unique insights each healthcare discipline brought to the general ethical dilemmas. For example, nursing students noted not only specific groups of the population impacted by lack of health insurance, but also consequences of not getting the appropriate care such as insulin or chemo treatments; therapy students noted the ethical challenge of health insurance running out before all necessary treatments were provided; and healthcare administration students identified fiscal concerns as driving forces within their organization. Overall, all the clinical disciplines (nursing, therapy and medical students) brought out some health treatment implications of the uninsured, while the healthcare administration students did not recognize this aspect of the uninsured. Likewise, many healthcare administration students recognized the fiscal consequences for society and organizations, which fewer clinical students recognized. These differences fall within the domain of students' chosen professions. Clinical students have the clients' care and health status as their primary concerns, while healthcare administration students must be responsible for the survival of their healthcare organizations, whether a hospital, physician practice or community health center.

\section{IMPLICATIONS AND CONCLUSION}

Upon reflection of our findings, several academic and professional implications are identified; i.e. the need to incorporate student perspectives within learning experiences, the responsibility to provide students with skills to improve healthcare services, and the obligation to challenge our traditional method of teaching healthcare ethics.

As noted earlier, ethics education programs must provide students with knowledge of ethical foundations and decision-making models. However, somewhere within the learning experience, professors must take the time to hear what their students believe. This basic step within the learning process is vital in teaching from a studentcentered philosophy and ensuring that students leave academia with the ability to integrate ethical concerns in their thinking and actions. From our literature review, it appears that while we are good at providing our students with the latest studies and models of ethical analysis, we are not as vigilant in taking the time to hear our students' interpretation of our system's ethical dilemmas. Healthcare students bring with them valuable, first-hand experiences which professors can work with when designing and teaching healthcare ethics.

The second implication is our responsibility, as educators, to provide students with skills and insights to improve healthcare services. As noted in our findings, healthcare disciplines provide different perspectives of ethical dilemmas. Swetz, Crowley, Hook, and Mueller (2007) found that $76 \%$ of all the ethics consultations conducted at the Mayo Clinic from 1995 to 2005 involved "staff member disagreement with care plans." Educators have the responsibility to facilitate understanding among healthcare professionals. Each healthcare professional already contributes a great deal individually; however, much more can be achieved through listening and understanding others' perspectives and working together to plan patient care. Our students need the opportunity to develop skills to work together with various healthcare staff. These skills include listening and sharing perspectives, as well as incorporating multiple professionals in the provision of effective and efficient healthcare services.

These implications lead to a third consideration - the challenge of working within traditional university curriculums. The structure of universities and colleges largely reflects the traditional professional silos built by healthcare disciplines. Each healthcare discipline has its own curriculum which reflects the core competencies needed for safe practices. However, a close examination of these core competencies (and needed skills) reveal several which overlap (Verma et al., 2009). We suggest that the competency of recognizing ethical concerns, working with and incorporating different perspectives in care planning represents a set of skills, knowledge and attitudes necessary for the comprehensive practice of healthcare. Canada has spearheaded several initiatives to educate healthcare students together for their core competencies (Verma et al., 2009). We suggest that healthcare ethics be required as a multi-disciplinary course or experience. At first this may seem to be a radical recommendation, but incorporating multiple disciplines can not only enhance our graduates' skills, but enhance the outcomes of healthcare services.

The findings from this study identify a need within the academic community and should awaken a significant discussion. When and how are professors learning about the ethical dilemmas students perceive in the healthcare settings? When and how are clinical students communicating with other clinical disciplines, as well as administration students, and developing skills to work together? As universities struggle to keep up with providing the most effective educational experiences, educators must address the challenge to teach cross disciplinary. 


\section{AUTHOR INFORMATION}

Janet R. Buelow (Ph.D., University of Illinois) is an Associate Professor of Healthcare Administration. Her research interests include interdisciplinary education and effective management practices in health and long-term care organizations.

Pamela L. Mahan, (DSN, University of Alabama at Birmingham) is an Assistant Professor in the Department of Nursing. Her research interests encompass health promotion and disease prevention, and health disparities. She is engaged in ongoing research in ethics and empathy.

April W. Garrity (Ph.D., Louisiana State University) is an Assistant Professor in the Department of Communication Sciences and Disorders. She holds the Certificate of Clinical Competence in speech-language pathology from the American Speech-Language Hearing Association. Her research interests include language acquisition and impairment across the lifespan and various clinical populations, linguistic variation, and effects of pedagogical approaches on learning. All authors are currently employed at Armstrong Atlantic State University, 11935 Abercorn Street, Savannah, Georgia 31419-1997.

\section{REFERENCES}

1. Callister, C.L., Luthy, K., Thompson, P., \&. Memmott, R.J. (2009). Ethical reasoning in baccalaureate nursing students, Nursing Ethics, 16(4), 499-510.

2. Geddes, E.L., Wessel, J. \& Williams, R. (2004). Ethical issues identified by physical therapy students during clinical placements, Physiotherapy Theory and Practice, 20, 17-29.

3. Gorgulu, R.S. \& Kinc, L. (2007). Ethics in Turkish nursing education programs, Nursing Ethics, 14(6), 741-752.

4. Jensen, G. \& Richert, A. (2005). Reflection on the teaching of ethics in physical therapist education: Integrating cases, theory, and learning, Journal of Physical Therapy Education, 19(3), 78-85.

5. Kenny, B.J., Lincoln, M., Blyth, K., \& Balandin, S. (2009). Ethical perspectives on quality of care: The nature of ethical dilemmas identified by new graduate and experienced speech pathologist. International Journal of Language \& Communication Disorders, 44(4), 421-439.

6. Lazarus, C.J., Chauvin, S. W., Rodenhauser, P, \& Whitlock, R. (2000). The program for professional values and ethics in medical education. Teaching and Learning in Medicine, 12(4), 208-211.

7. Nolan, P. W., \& Smith, J. (1995). Ethical awareness among first year medical, dental and nursing students. International Journal of Nursing Studies, 32(5), 506-517.

8. Shaw, H.K, \& Degazon, C. (2008). Integrating the core professional values of nursing: A profession, not just a career. Journal of Cultural Diversity, 15(1), 44-50.

9. Sporrong, S. K., Arnetz, B., Hansson, M.G., Westerhom, P., \& Hoglund, A. (2007). Developing ethical competence in healthcare organization. Nursing Ethics, 14(6), 825-837.

10. Swetz, K.M., Crowley, M.E., Hook, C.C., \& Mueller, P.S. (2007), Report of 255 clinical ethics consultations and review of the literature. Mayo Clinic Proceedings, 82(6), 686-691.

11. Thustall-Pedoe, S., Rink, E., \& Hilton, S. (2003). Student attitudes to undergraduate interprofessional education. Journal of Interprofessional Care, 17(2), 161-172.

12. Verma, S., Broers, T., Paterson, M., Schroder, C. Medves, J.M. \& Morrison, C. (2009). Core competencies: The next generation; comparison of a common framework for multiple professions. Journal of Allied Health, 38(1), 47-53 